MUHAMMAD QASIM, M.Sc. ${ }^{1}$

(Corresponding author)

E-mail: qasimm264@gmail.com

CSABA CSISZÁR, Ph.D. ${ }^{1}$

E-mail: csiszar.csaba@kjk.bme.hu

${ }^{1}$ Department of Transport Technology and Economics

Faculty of Transportation Engineering

and Vehicle Engineering

Budapest University of Technology and Economics

Müegyetem rkp. 3, 1111 Budapest, Hungary
Transport and Sustainable Development Original Scientific Paper Submitted: 20 June 2021 Accepted: 21 Oct. 2021

\title{
MAJOR BARRIERS IN ADOPTION OF ELECTRIC TRUCKS IN LOGISTICS SYSTEM
}

\begin{abstract}
The article analyses the issues concerning the reluctance of logistics professionals to adopt medium-sized electric trucks (ET) in the logistics system. Logistics trucks are oversized polluters, considered to be one of the hardest to be addressed for the reduction of $\mathrm{CO}_{2}$ emissions. It aims to identify the major barriers hindering the spread of ETs in logistics. The total cost of ownership (TCO) comparison between a traditional and electric truck has revealed the price gap at the end of a useful lifecycle is marginal. Incentivisation can bridge the gap. This research was based on a survey conducted among professionals from the logistics field in Budapest. Responses recorded were analysed by descriptive statistics to identify highly-rated barriers and their priorities. Based on the results, recommendations were suggested to facilitate the adoption of ETs.
\end{abstract}

\section{KEYWORDS}

logistics system; electric truck; adoption; incentive; total cost of ownership.

\section{INTRODUCTION}

Along with the increasing growth of international trade and globalisation, the volume of transported goods is increasing. Conventional delivery trucks significantly contribute to the local (traffic congestion, NOx and noise pollution, etc.) and global (Green House Gas $=\mathrm{GHG}$ emissions) environmental impacts, directly affecting the urban residents. The transport sector is currently responsible for around a quarter of total $\mathrm{EU} \mathrm{CO}_{2}$ emissions. Heavy-duty vehicles in Europe account for 5\% of Europe's GHG emissions [1]. Under the Paris Agreement, the European Union has made arrangements to ensure that all economic sectors contribute to decarburisation. By 2030, sectors not included in the ETS, such as transport, must reduce emissions by $30 \%$ compared to 2005 and reach $94 \%$ [2]. Since some transport sectors are more difficult to fully decarbonise (e.g. aviation), it is essential that all road vehicles that burn fossil fuels are replaced with zero-emission vehicles to achieve these reductions.

Given the flexibility of trucks, their speed, their cost advantage, and the overhaul needed in the rail sector to reach its full potential, trucking is likely to maintain a market share that does not deviate significantly from its current $75 \%$ [3]. For these reasons, this work focuses on the major barriers hindering the adoption of electric trucks in the trucking sector.

The World Health Organisation states that poor air quality is a serious environmental issue. Many European cities do not meet the European standards for air quality leading to penalties. One of the major short-term concerns for local authorities is to improve local air quality. In the longer term, the European Commission plans to make urban freight transport emission-free by 2050 . To meet the longterm targets, trucks need to achieve zero emissions. Battery electric truck (BET) is an emerging technology to achieve this purpose. Lack of economic, operational, and environmental competitiveness and charging infrastructure barriers hinder the electrification process. However, from a business point of view, BETs are economically attractive. Considering that more than $80 \%$ of the urban freight distributions are within $80 \mathrm{~km}$ in European urban areas, electric trucks are an attractive solution to lower the emissions [4]. Electrification of heavy-duty vehicles could contribute to a better life in urban areas by reducing tailpipe emissions. However, the adoption of electric trucks still concerns the suppliers regarding their economic competitiveness with conventional trucks [5]. Electric vehicles adopted in a small 
percentage of the fleet are beneficial both economically and environmentally. Due to the initial stage of experimentation with electric cargo cycles, there are still cautions and concerns from logistics suppliers which can only be diminished through risk-sharing with relevant stakeholders [6].

Electrification of heavy-duty vehicles is inevitable to make the logistics sector clean and sustainable. The European Union has issued a clean mobility directive to member states to achieve electrification of the heavy-duty vehicles as per prescribed targets. However, heavy-duty vehicles are making slow progress in the logistics market. It is essential to identify the barriers hindering the way of electric trucks in the logistics sector by considering the concerns of the logistics professionals.

The main objective of this research paper is to highlight the barriers that are hindering the adoption of electric trucks (ETs) in the logistics sector to ease the decision-making for the local authorities to support the uptake of ETs. We also highlighted the strengths, weaknesses, opportunities, and threats for electric trucks. Local authorities are aiming to meet the goals set by the EU commission to meet the transport sector electrification. As the EU Commission has given targets to the member states for electrification of the transport sector, determination of major barriers for an electric truck in logistics sectors is a pre-requisite to support the electrification of the logistics sector. Determination of major barriers also brings the attention of manufacturers towards the much-needed improvements and business opportunities in the logistics sector.

The remainder of the paper is structured as follows. State of the art compares some inclusions of electric vehicles in the logistics sector and highlights the financial support received by the local authorities. The methodology section comprises a methodological framework that includes the total cost of ownership calculation (TCO), SWOT analysis, and a survey that is conducted among logistics service providers of Budapest, Hungary. TCO calculation and SWOT analysis for ETs were performed in comparison to conventional internal combustion engine trucks (ICET). Accordingly, it has been revealed that ETs have the potential to replace the ICETs and also meet the European commission goals. Logistics companies working in $\mathrm{Bu}-$ dapest were sorted based on their operational range and supply chain system strength. The sample size consisted of $20 \%, 30 \%$, and $50 \%, 2 \mathrm{PL}, 3 \mathrm{PL}$, and
4PL companies respectively. The barriers to ETs adoption in the logistics sector have been identified based on our survey. A questionnaire-based survey followed by a multi-criteria descriptive analysis was the primary methodology adopted to achieve the results.

Discussion of results explains the major barriers that were highlighted by the respondents and also highlighted the route optimisation opportunity that can be part of future works. The recommendations section includes recommendations for local authorities, original equipment manufacturers (SMEs), and business organisations to support the growth of ETs. Finally, the conclusions are drawn and major contributions as well as the key findings of the paper are summarised. We provided lessons learned and the limitations of our research. Our future works address additional TCO scenarios, the effect of relocation of urban consolidation centres, and route optimisation scenarios.

\section{STATE OF THE ART}

In view of global and local emission reduction targets and motivated by the foreseeable reduction in oil resources, research and industry have begun to seek solutions for the electrification of commercial vehicles, namely heavy commercial vehicles [7]. Because exhaust fume emissions must be minimised, the answers to these questions seem to be essential in the development of low-emission logistics. Electrification of commercial vehicles could reduce emissions and thus contribute to a better quality of life in cities. However, the use of electric trucks still raises concerns among suppliers regarding operational competitiveness (operating and procurement costs, vehicle performance) compared to conventional diesel trucks.

Although the operating costs of electric trucks are lower, they do not stand out enough based on the total cost of ownership. Electric truck acquisition costs remain high and can have a negative impact on operational competitiveness. Results of ELCIDIS (Electric Vehicle City Distribution), a successful project commissioned by the European Union, identified the higher acquisition cost of electric trucks as a prime obstacle to widespread implementation of electric trucks [8]. Another similar research concludes that electric trucks are only competitive if acquisition cost drops for at least $30 \%$ and if its 
utilisation rate is higher [9]. Multiple research results refer to the initial cost of purchase as a major barrier to the inclusion of electric trucks in the fleet.

Sixty-eight inventory instances and twenty-seven in-depth studies given throughout the Best Urban Freight Solutions (BESTUFS) project reveal a mix of trends toward a more sustainable logistics strategy. The findings reveal that commercial considerations continue to guide the transportation and logistics industry's operations, with profitability and competitiveness being the key factors influencing project adoption. Freight transport and logistics are business activities and are driven by these fundamental dynamics. Key players in logistics and freight transport are undertaking a variety of initiatives, some developed internally, while others have emerged thanks to the involvement of public authorities and other government bodies [10]. The high adoption rate for electric cars in the last few years also raises questions over the low inclusion of electric trucks in the logistics fleet. ETs have been adopted on pilot testing several years ago and many European countries have started pilot projects [11]. Some of these projects are linked with electric vans. Electric vans make deliveries from urban consolidation centres. These inventories show a growing interest in electric deliveries that are becoming more and more popular.

Another similar research concludes that long haul trucking is feasible, it significantly reduces greenhouse gas emissions, and would make sense for rational economic decisions. A report on the decarbonisation of road freight transport found that electric trucks are the most energy-efficient solution for decarbonisation [12]. The E-highway technology developed by Scania and Siemens is an example of the decarbonisation of long-distance freight transport. Motorways are a fascinating proposition and may be more profitable than BETs for long-distance transport (including infrastructure construction), as ongoing trials in Sweden and Germany show that they are already technically feasible [13].

We have collected case studies of the deployment of ETs in logistics systems in recent years. It has been observed that ETs can operate efficiently with a limitation on payload. Some of the exemplary case studies are summarised in Table 1. State of the art of case studies has shown in most pilot operational projects that medium-sized ETs are successful with dedicated routes and charging infrastructure. The majority of the projects are non-incentivised and are either run for marketing by manufacturers or by a private company for achieving personal goals. The ETs market is lagging in attracting financial support from the authorities.

Table 1 shows that a few pilot implementations of electric trucks with different sizes (1-14 tons) and different ranges $(97-315 \mathrm{~km}$ ) have been introduced. Out of the four projects mentioned, only one project is incentivised by the regional authority while all other projects lack financial support from local and regional authorities. Lack of support from the authorities is one of the long-lasting and major barriers to the growth of electric trucks. With the EU Commission imposing national and regional goals for electrification of the transport sector, support of authorities will be pivotal for the stakeholders of the logistics transport sector.

Table 1 - Comparison of case studies

\begin{tabular}{|c|c|c|c|c|c|c||}
\hline City, Country & Project & Purpose of use & $\begin{array}{c}\text { Payload } \\
\text { limit }\end{array}$ & Range & Incentives & $\begin{array}{c}\text { Project } \\
\text { STATUS }\end{array}$ \\
\hline \hline $\begin{array}{c}\text { Perg, } \\
\text { Austria }\end{array}$ & $\begin{array}{c}\text { E-CEP-Service-Trial } \\
\text { by Greenway }\end{array}$ & $\begin{array}{c}\text { Logistics for short } \\
\text { distances }\end{array}$ & $1-6 \mathrm{t}$ & $\sim 180 \mathrm{~km}$ & $\begin{array}{c}\text { No incentive, result of } \\
\text { collaboration }\end{array}$ & Operational \\
\hline $\begin{array}{c}\text { Stuttgart, } \\
\text { Germany }\end{array}$ & $\begin{array}{c}\text { Trial service by } \\
\text { Porsche }\end{array}$ & $\begin{array}{c}\text { Logistics for short } \\
\text { distances }\end{array}$ & $32 \mathrm{t}$ & $\sim 130 \mathrm{~km}$ & $\begin{array}{c}\text { No incentive, pilot } \\
\text { project by vehicle } \\
\text { manufacturing com- } \\
\text { pany }\end{array}$ & $\begin{array}{c}\text { Pilot program } \\
\text { operational }\end{array}$ \\
\hline $\begin{array}{c}\text { Amsterdam, } \\
\text { Lisbon, Portherlands }\end{array}$ & $\begin{array}{c}\text { Freight electric } \\
\text { vehicles in urban } \\
\text { Europe }\end{array}$ & $\begin{array}{c}\text { Small-scale logis- } \\
\text { tics in many cities } \\
\text { as a trial. }\end{array}$ & $1-14 \mathrm{t}$ & $\sim 315 \mathrm{~km}$ & $\begin{array}{c}\text { Funded by the EU, } \\
\text { part of 2021 goal to } \\
\text { achieve CO } \text {-free } \\
\text { logistics }\end{array}$ & Operational \\
\hline Europe wide & Lightning systems & To be implemented & $2 \mathrm{t}$ & $97 \sim 193 \mathrm{~km}$ & $\begin{array}{c}\text { No incentives, private } \\
\text { project }\end{array}$ & $\begin{array}{c}\text { To be } \\
\text { implemented }\end{array}$ \\
\hline \hline
\end{tabular}




\section{LITERATURE REVIEW}

This section briefly reviews the literature related to the introduction of ETs and the major problems faced. Three major aspects (economic issues, environmental concerns, and operational issues) are addressed in detail. In recent years, the ever-growing demand for public and freight transport has worsened the negative impacts of mobility on the environment and society. Growing demand is causing a substantial increase in traffic congestion, air pollution, and climate change cost. Adoption of green and sustainable technologies in the transport sector is the need of the hour [14]. High initial price, charging time, and limited range are the obstacles towards the adoption and diffusion of EVs [15]. Deployment of EVs has been a key measure to reduce pollution in urban areas caused by the logistic sector. Meanwhile, the electrification of the logistics fleet has been slowed by a lack of support from the government and insufficient charging infrastructure [16].

The study compares the total costs - including purchase, salvage revenue, and operational \& management costs. The initial buying cost of EVs is higher than that of internal combustion engine vehicles (ICEVs) mainly due to the high cost of batteries. Meanwhile, the large taxes on vehicles and fuels have given the government enough influence over the automobile market. The introduction of incentives by the government enabled niche market actors to take advantage of ETs business growth while simultaneously weakening the ICEVs market [17].

During the total cost of ownership analysis, it has been revealed that the electricity price causes the biggest sensitivity to cost competitiveness. Road charging discount that may be applied to zero-emission trucks on motorways is also an important factor [18]. Last years have shown a rapid increase in the number of trials and pilot implementation of ETs. In some cities (e.g. Trondheim, Lisbon, London, Amsterdam, etc.) clean electricity sources are fully recommended to achieve greater health benefits and to minimise pollution. Location of charging stations over the routes is very critical and it directly affects the route choice. Online guidance for finding charging opportunities can significantly increase the range of EVs [19].

Electric trucks contribute less to air quality compared to conventional trucks. As electricity production is usually away from populated areas while tailpipe emissions of the conventional trucks directly affect the people nearby [20]. Over the life period, ETs consume $28 \%$ less energy and emit $38 \%$ fewer GHGs in comparison to their counterpart [21].

The benefits of BETs are valued more than ICEVs and some measures are needed to highlight them. Important measures are to develop extensive charging infrastructure and to introduce financial incentives through tax exemptions [22]. One of the most important issues that needs to be addressed by local authorities is to contribute heavily to the expansion of incipient infrastructure, i.e., deploying more charging stations to make the spread smoother. The wide uptake of ETs is slowed down by the high manufacturing cost, little variety available in the type of vehicle, low range, and insufficient supporting infrastructure [23]. Precise determination of the location of refuelling stations can affectively increase the operational range of ETs [24]. The development of a dynamic forecasting model that is capable of parking occupancy of a truck can help in the determination of a suitable location for charging infrastructure [25]. Selecting a suitable zone is detrimental for accurate forecasting of traffic and provision of infrastructure [26].

Optimal siting of charging infrastructure is one of the key factors for the success of EVs and inadequate placement may lead to range anxiety [27]. BEVs are well suited for cargo transportation than rival conventional trucks saving $60 \%$ of energy usually consumed by delivery vehicles [28]. Logistics systems are changing dynamically to respond to the demand of the environment and society. Significant changes in demand are leading logistics to decentralisation and individualisation. The optimal location of charging infrastructure in the case of logistics trucks should be determined and it should be achievable as logistics trucks usually have fixed routes compared to free-floating cars [29]. The adoption of smart logistics techniques (autonomous vehicles, artificial intelligence, etc.) will help to make direct communication between decentralised logistics systems [30]. Studies have revealed that the preferences of the transport and logistics staff impact the scheduling. Considering the preferences of the transport and logistics staff may increase the possibilities of a more efficient formulation scheduling of the fleet [31].

"The relative benefit of electric trucks over diesel counterparts could be much more significant than one might expect," said Lee. "If the electric truck is deployed in the right drive or duty cycle application, 
fleet operators could enjoy higher returns on investment, while saving energy and reducing greenhouse gas emissions" [32]. Recent results have proved that improvement in the efficiency of ETs is considerably higher than the ICETs for different weight classes, vehicle types, and duty cycles. Vehicle energy efficiency ratio is $\sim 3.5$ at highways and 5-7 times of ICET. The results show that the efficiency improvement of battery electric vehicles is considerably higher than conventional diesel vehicles for different weight classes, vehicle types, and duty cycles. The vehicle energy efficiency ratio is about 3.5 at highway speeds and 5 to 7 times the efficiency of conventional diesel vehicles when operated at lower speed duty cycles where idling and coasting losses from conventional engines are highest [32].

Comparison of electric trucks with conventional trucks in mix vehicle problems have revealed that a fleet size reduces the overall cost of distribution if different technologies are used as a mix. In shortrange urban distribution, electric trucks are more cost-efficient [33].

The literature review summarises that electric vehicles have the potential and efficiency to replace conventional ones in the logistics sector. However, major barriers need to be highlighted for ease of stakeholders and local authorities to take decisions of support. During a thorough literature review, we revealed that most of the barriers highlighted are mentioned in theoretical studies or resulted from pilot implementations of ETs. Identification was more based on the user's/authorities' perspective while logistics professionals were not as involved. We covered the gap by directly enquiring the logistics professionals about their willingness and concerns to buy the electric vehicles for their fleet. It has been revealed that logistics professionals are expecting incentives from the local authorities.

\section{METHODOLOGY}

A questionnaire was designed to determine the reasons for the reluctance of companies towards ETs and their expectations from authorities that can encourage them to adapt to the novel mode. The questionnaire was sent to 60 companies. A pre-defined set of barriers based on literature review were included in the questionnaire as highlighted in Figure 1. In the initial phase, selected companies were contacted by emails and there was no response even after repeated reminders. The language barrier, busy schedule, and inadequate contact methods were the causes of no response. In the next phase, logistics companies were visited in person to get a response. A big portion of the responses was collected from 3PL and 4PL companies (90\%).

Figure 2 summarises the four phases of a framework of methodology and the sub-activities conducted to achieve the results. Phase IV summarises the recommendation to address the identified barriers and conclusions drawn according to the results.

Figure 3 shows the SWOT analysis (strength, weakness, opportunity, and threat) of both rival truck technologies. The SWOT analysis revealed low operational cost and eco-friendly operation are the biggest strength of the ETs. Deployment of ETs brings business and growth opportunities for the battery and charging infrastructure providers. On the other hand, high procurement cost, limited range, low payload capacity, lack of charging infrastructure, and grid load issues remain the weakness for the introduction of ETs in the logistics sector.

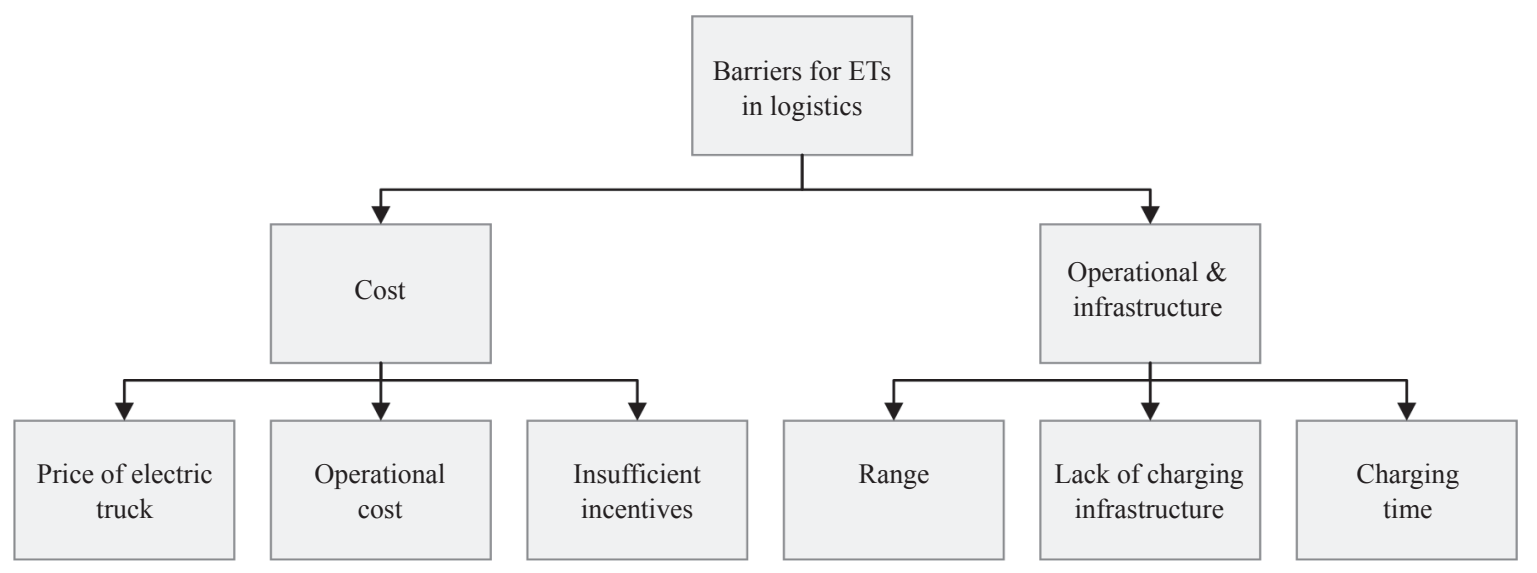

Figure 1-Categorisation of potential barriers 


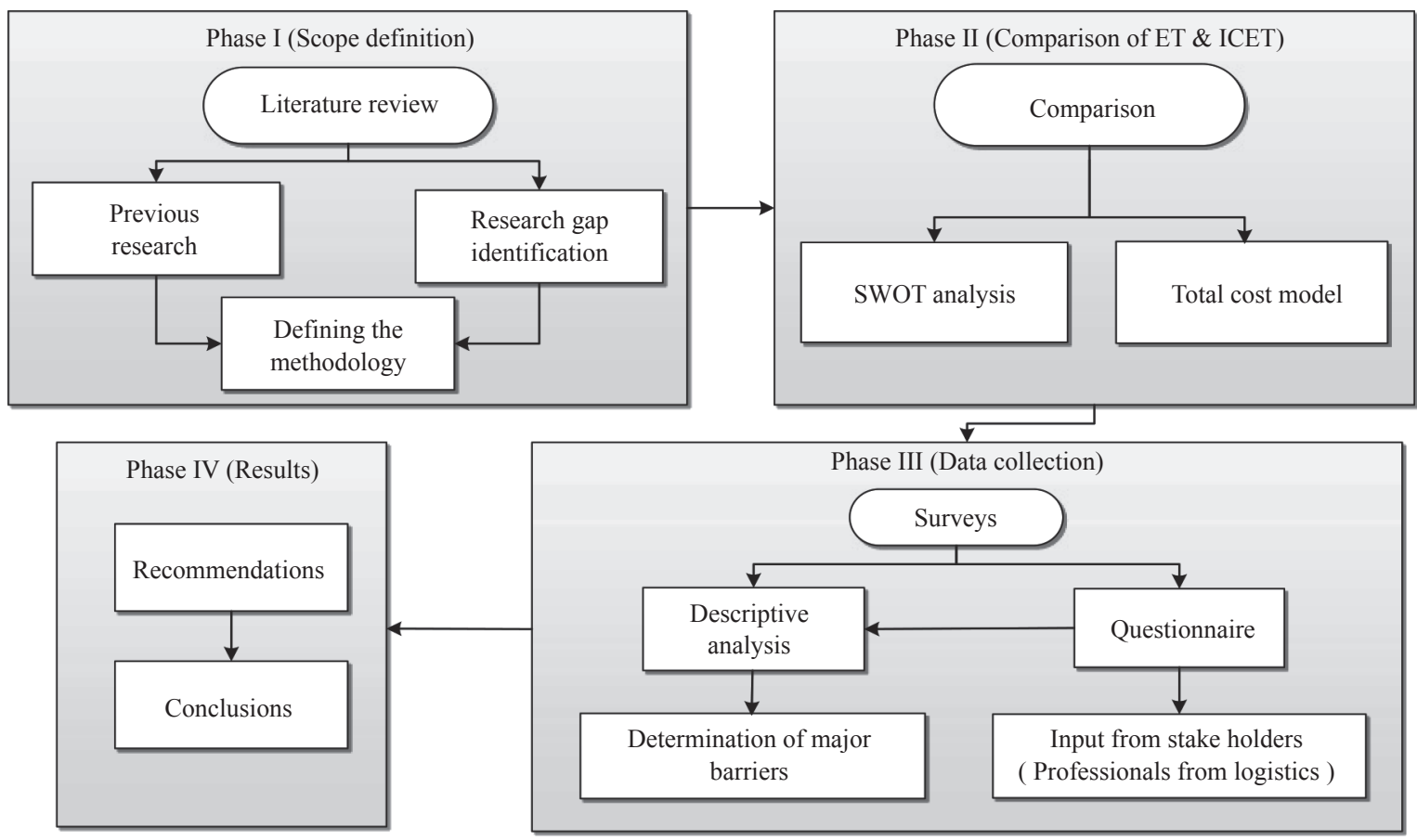

Figure 2 - Hierarchical framework of methodology

\begin{tabular}{|l|l|}
\hline Strengths & Weakness \\
- Fuel cost & - Procurement cost \\
- Environmentally friendly & - Low capacity \\
- Less noise pollution & - Limited range \\
- Partially autonomous & - Lake of charging \\
& opportunities \\
& - Grid issues \\
& \\
\hline & \\
Opportunities & Threats \\
- Decrease in battery & - No clear regulations \\
price & for support \\
- Cheaper charging & - Low oil prices \\
facilities & - Increase in electricity \\
- Growth in market & price \\
of ETs & - Increase in efficiency \\
& of ICTS \\
\hline
\end{tabular}

Figure 3 - SWOT analysis for ETS

Low prices of fossil fuels, no regulations for financial support of ETs, increase in electricity prices, and increase in efficiency of ICETs remain the threats to the uptake of ETs in logistics.

\subsection{Research instrument}

A questionnaire was designed based on Google Forms to collect data electronically from the target group, i.e., logistics companies. Printed hard copies were also used in the second phase of data collec- tion. The author himself visited the target companies and explained the questions to obtain the most authentic response. Collected data was then analysed in Microsoft Excel to highlight the key findings.

\subsection{Research participants}

A sample size of 60 companies was selected to collect the response. 60 companies were contacted in Phase I and 36 companies were contacted in person. The sample size consisted of $20 \%, 30 \%$, and $50 \%, 2 \mathrm{PL}, 3 \mathrm{PL}$, and 4PL companies respectively. Table 2 below explains the characteristics of companies selected for the sample size.

A detailed comparison of a conventional diesel truck and an equivalent ET was compiled. The methodology includes the following steps. The first step includes a comparison of the total cost of ownership (TCO) over the lifecycle of both rivals. TCO is calculated to highlight the main contributors to

Table 2 - Characteristics of logistics companies selected for study

\begin{tabular}{||c|c|c|c||}
\hline $\begin{array}{c}\text { Company } \\
\text { ownership }\end{array}$ & $\begin{array}{c}\text { Hungarian } \\
\text { (Government) }\end{array}$ & $\begin{array}{c}\text { Hungarian } \\
\text { (Private) }\end{array}$ & $\begin{array}{c}\text { Private } \\
\text { (Foreign } \\
\text { origins) }\end{array}$ \\
\hline \hline Company size & $2 \mathrm{PL}$ & $3 \mathrm{PL}$ & $4 \mathrm{PL}$ \\
\hline $\begin{array}{c}\text { No. of } \\
\text { employees }\end{array}$ & $<20$ & $>20<50$ & $>50$ \\
\hline
\end{tabular}


the overall price gap between the ETs and conventional trucks. The price gap needs to be filled by the support of local and regional authorities to support the uptake of ETs. The TCO for ETs and ICET is composed of fixed cost (net purchase price, tax, and insurance) and variable price (tires, maintenance price, fuel and coolant packages, etc.). Tax, insurance, and operator cost are assumed to be the same for simplification in calculations (assuming no subsidy from government authorities).

Assumptions considered for the calculations:

- Average diesel fuel price 0.7 Euro/litre.

- Variable cost is based on 8,000 km of monthly running and the average operational age of a truck is 10 years.

- The average cost of maintenance and repair cost of the electric truck is $40 \%$ of a conventional truck with no engine, TM oil, cooling package, timing belt, water pump, fuel filter, and engine air filter, replacement, etc. The SEV Newton maintenance cost has been reported to be only about $10 \%$ of its diesel truck counterpart. [34] However, we have assumed that the maintenance and repair cost of electric trucks to be $40 \%$ of a conventional truck as powertrains have yet to prove their reliability for the ETs.

Batteries have improved their economic strength in 30 years. The price of lithium-ion cells considering their energy capacity has declined about $97 \%$ since their introduction in the commercial market. As of 2020, the battery price of the electric truck is estimated to be $\$ 140$ per $\mathrm{kWh}$. Assuming the battery life cycle $(2,800$ cycles at $\sim 100 \%$ depth of discharge) [35] and operation range $\sim 10,000 \mathrm{~km}$ in a lifetime. It is estimated that no replacement will be needed. Nonetheless, as the Li-ion battery is a progressive technology, interventions may be expected. Electricity as a fuel is estimated to cost $\sim 10 \mathrm{c} / \mathrm{kWh}$. Energy consumption for a medium-sized delivery truck is $\sim 480 \mathrm{Wh} / \mathrm{km}$. The operating cost associated will be $\sim 5 \mathrm{c} / \mathrm{km}$. For a diesel truck, it will cost about $\sim 15 \mathrm{c} / \mathrm{km}$ to operate. For $8,000 \mathrm{~km}$ running every year, ET will save $\$ 1,200$ per year [36].

Accumulated savings of $\$ 6,000$ combined with a residual value of battery after five years of warranty can contribute well for replacement of the battery. For TCO comparison, 49-tonne GCW HD diesel truck and electric truck (Tesla Semi) were compared for an average operational age. Fixed and variable costs can presumably vary by $10 \%$ from company to company. TCO comparison showed that the initial investments for ETs and ICETs are separated by a huge price gap. The initial buying cost of ETs is way higher $(\sim 450 \%)$ than its competitor, whereas when the operational and maintenance cost over the average operational life of vehicles is taken into account, the price gap narrows down. The operational and maintenance cost of ETs is much cheaper (230\% lower) compared to the conventional ICETs.

The operational cost of ETs is lower as ETs do not have a high fuel cost, urea, and oil cost. Statistical analysis of the TCO results revealed that ETs costs only 1.05 times the ownership cost of the conventional ICETs as shown in Figure 4 given below. By the end of the TCO lifetime comparison, there is still a small gap in overall cost that can be decreased if following suggested measures.

- High fixed costs can be decreased by decreasing VAT/taxation, incentivisation by local authorities, by starting production of ETs locally, and by outsourcing in bulk from low-cost countries like India and China.

- Controlling the price of diesel fuel as fluctuation in the price of diesel can significantly affect the case of ETs.

- Electric power supply issues can be addressed by the production of batteries locally and by the provision of financial support to the charging infrastructure of ETs.

A comparison of costs was made to highlight the components that were causing a major difference in the cost of ownership between the electric trucks and conventional trucks. High cost-causing components (batteries and fossil fuels) help in the determination of strengths and weaknesses of the vehicle for future growth. Future growth is dependent on regional goals of sustainability and the eco-friendly transport sector.

Phase III includes compiling a questionnaire to collect the response of logistics professionals and perform the required statistical analysis to highlight the barriers. The questionnaire consisted of four sections for the sake of convenience of response collections as shown in Table 3. The four sections asked about the company's profile, general knowledge about ETs, driving and parking patterns, and their expectations from ETs respectively.

Section 1 enquired responders about the size of the company, number of employees, and the type of company (2PL, 3PL, and 4PL, etc.). Section 2 asked responders if they are familiar with ETs or if they already have ETs in their fleet. Responses of only those companies who responded yes to familiarisa- 


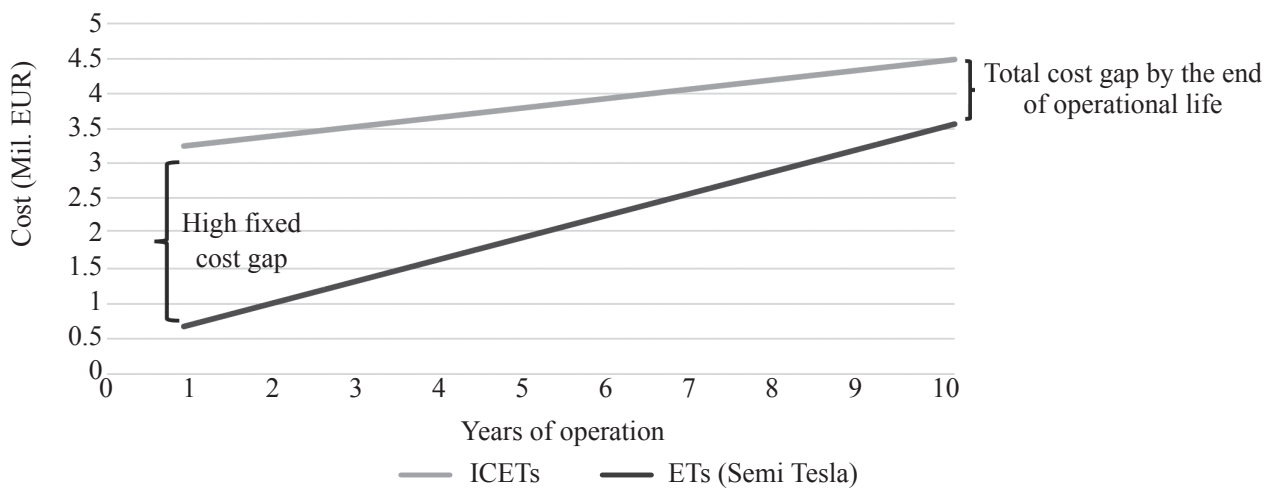

Figure 4 - Total cost of ownership comparison between ICETs and ETS

Table 3 - Breakup of questionnaire section-wise

\begin{tabular}{||c|c|c|c|c||}
\hline \multicolumn{5}{|c||}{ Questionnaire } \\
\hline \multicolumn{4}{|c||}{ Determination of major barriers in the adoption of electric trucks in logistics system } \\
\hline \hline $\begin{array}{c}\text { Information about } \\
\text { responding company }\end{array}$ & Kection 2 & Section 3 & Section 4 & Section 5 \\
\hline \hline
\end{tabular}

tion with ETs were considered for the compilation of results. Section 3 collected responses about operational range, mobility pattern (single/multi-step), daily average distance travelled by truck, location of the consolidation centre (UCC) with respect to the city centre, frequency of return to the parking garage/ day, and parking duration/day at a company-owned parking garage. Section 4 collected responses about the perception of responders about the range of ETs, price of ETs, charging time of ETs, operational cost, and monetary support by local authorities.

\section{RESULTS}

In the questionnaire, logistics professionals were provided with potential barriers to determine their preferences. Responses for the relative importance of the barriers were compared. The most important barriers were highlighted. Priorities for possible incentives and expectations of logistics companies from government/authorities have been revealed. A sample size of 60 companies was selected to collect the response. 60 companies were contacted in Phase I and 36 companies were contacted in person. The sample size consisted of $20 \%, 30 \%$, and $50 \%, 2 \mathrm{PL}$, 3PL, and 4PL companies respectively.

During Phase II, 30 responses were considered fit for analysis; six responses were ignored as the data received was too confusing. The calculated data set in the previous chapter is discussed here in the graphical form and the results are explained.

Results of the survey revealed that $23 \%$ of logistics companies have their urban consolidation centre (UCC) near the city centre while $77 \%$ of companies have their UCC in the suburbs of the city (Figure 5). Statistical analysis revealed that those logistics companies having UCC near the city centre have relatively lower daily average distance travelled (DADT) compared to companies having UCC in the suburbs of the city. Figure 1 shows that $75 \%$ of companies with UCC near the city centre have their DADT range $50-200 \mathrm{~km}$, which is very much possible to be easily covered with available ETs (Figure 6).

Figure 7 shows the DADT of companies with their UCC in the suburbs of the city. For companies with the UCC in the suburbs, it was shown that $91 \%$ of their trucks have DADT $>200 \mathrm{~km}$ and $48 \%$ of them have DADT $>300 \mathrm{~km}$. Results showed that these companies have a longer DADT than the other case mentioned above.

The response of logistics professionals showed their willingness to adopt ETs in their fleet. $27 \%$ of companies said that they are planning to buy an ET. 30\% of companies responded that if the government offers some incentives, they will include ETs in their fleet, while the rest of the companies responded that they do not plan to buy ETs (Figure 8). 


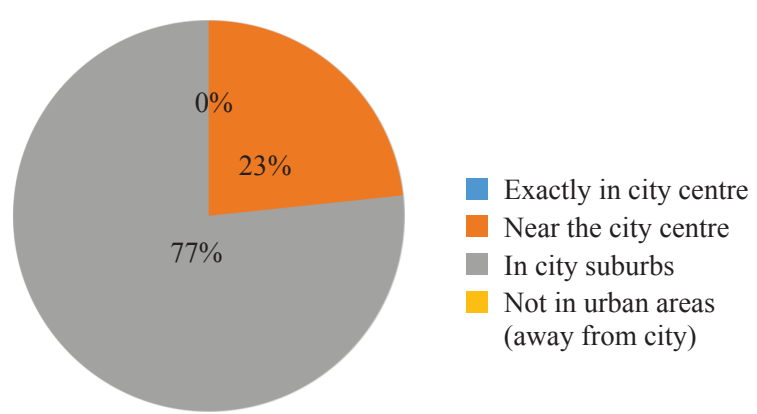

Figure 5 - Location of the consolidation centre with respect to the city

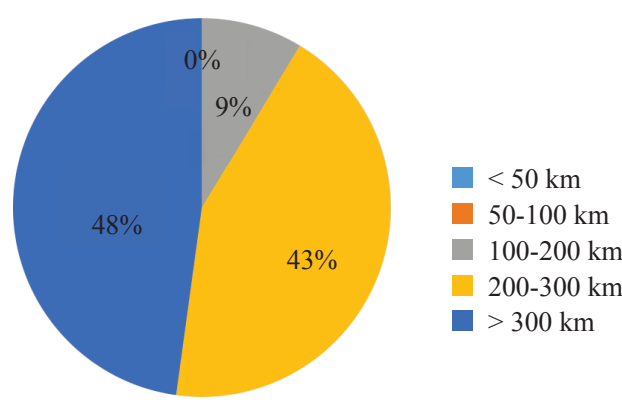

Figure 6-DADT of trucks with UCC near the city centre

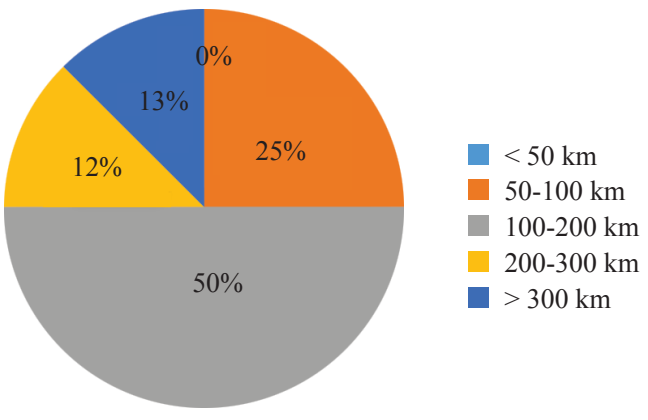

Figure $7-D A D T$ of trucks with UCC in suburbs

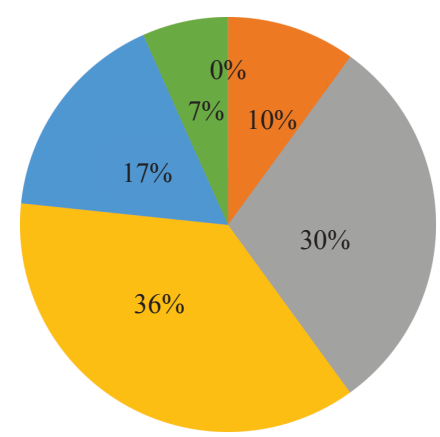

Yes (We are planning to buy a battery electric truck)

Yes (We are planning to buy a plug-in hybrid electric truck)

Yes (If government/authorities offer some incentives)

- No (We do not plan to buy an electric truck)

No (We do not own our fleet)

Maybe

Figure 8 - Willingness of logistics companies to adopt ETS

\section{DISCUSSION OF RESULTS}

Results of the study show a clear potential for the introduction of ETs in the logistics fleet. 53\% of the companies indicated that the average distance travelled by their trucks is less than $300 \mathrm{~km} /$ day. DADT by trucks when compared by the location of their UCC claimed that $43 \%$ of companies with the UCC near the city centre stated reported their DADT to be less than $200 \mathrm{~km}$, while $91 \%$ of companies with the UCC in suburbs of the city stated that their DADT is greater than $200 \mathrm{~km}$. As $73 \%$ of the companies indicated that their trucks follow the multi-step delivery pattern, it opens a window of intermediated charging for the trucks for traveling $>200 \mathrm{~km} /$ day. Although higher taxation and expensive land acquisition near the city centre affect this decision, the location of UCC also affects the distance travelled between the city and the UCC, causing extra fuel consumption, time, and labour costs as well. Therefore, a trade-off between the location of the UCC and DADT should be determined.

The analysis of mobility patterns showed that only $27 \%$ of companies operate on single-step (direct) delivery system, while the other $73 \%$ use a multi-step $(17 \%)$ and combined $(56 \%)$ delivery system. It shows an opportunity for the introduction of ETs because in the case of multi-step or combined delivery systems, longer distances are divided into relatively shorter distances and parking time is enough for charging. Multi-step delivery involves the running of trucks within the city with frequent stops. Frequent stops also support the case of ETs as they are equipped with a regenerative braking system.

Statistical analysis showed that $30 \%$ of the logistics companies are willing to adopt ETs in their fleet if some monetary support is offered by the government/ authorities, while $10 \%$ of companies have plans to buy hybrid trucks. $36 \%$ of logistics companies were not willing to adopt ETs because they are afraid of low range and inadequate charging infrastructure. $77 \%$ of companies pointed to long-range as the most influencing aspect to adopt ETs in their fleet.

Expectations of logistics companies towards incentives showed that $40 \%$ of them expect monetary aid for the purchase of the vehicle from the government, $23 \%$ expect lower electricity price, and 17\% lower taxes from the local government. Based on the survey, the following major barriers are identified for the spread of ETs in the regular heavy-duty transport sector. 


\subsection{Technological constraints}

Short-range and lack of charging infrastructure prevent many companies from the introduction of ETs in their fleet. $36 \%$ of the companies indicated that their trucks have a DADT $>200 \mathrm{~km}$ which is beyond the range of an average ET. While $40 \%$ of the companies claimed that DADT $>300 \mathrm{~km}$ collectively, $76 \%$ of the responses were not in favour of an average ET. This incapability of ETs generates range anxiety in the potential buyers. $67 \%$ of the respondents pointed to range anxiety as the reason for not willing to buy ETs, while the other 33\% of respondents showed their lack of trust in the density and capacity of the charging infrastructure.

Electric buses in comparison to ETs also suffer from similar technological limitations. However, electric buses have the advantage of following fixed routes and are not involved in stochastic delivery patterns. The European Commission is facilitating the clean bus deployment initiative based on, (i) a public declaration endorsing a common ambition of cities and manufacturers to accelerate the roll-out of clean buses; (ii) creating a deployment platform where public authorities, public transport operators, manufacturers, and financial organisations can come together with the aim to better exchange information, better organise relevant actors and create coalitions, leverage potential investment action and issue recommendations on specific policy topics; and (iii) creating an expert group bringing together actors from the demand and supply side. This expert group will benefit from consolidated expertise on technological, financial, and organisational issues [37]. ETs clearly lack such support from authorities.

\subsection{High investment costs - lack of incentives/monetary support}

The initial investment cost for ETs is almost four times higher than that of an ICET. Responses showed that high initial cost is one of the barriers preventing companies from investing in ETs, considering an average truck can be useful for roughly 10 years. Companies already owning ICETs will be looking to exhaust the existing fleets to maximum benefits while hoping for an announcement of incentives from local authorities to support ETs. As of 29 September 2014, the European Parliament passed a final directive for EU Member States to (i) develop national-level policies for the market developments of alternative fuels and the related infrastructure; (ii) foresee the use of common technical specifications for refuelling stations; and (iii) pave the way for setting up appropriate consumer information on alternative fuels, including a clear and sound price comparison methodology [38].

The EU Clean Vehicle Directive highlights that market of heavy-duty vehicles/trucks is still at an early stage and not as mature as the market for electric buses or other light electric vehicles. The slow response of the market in the production of electric trucks can also be understood through the goals defined by the EU Clean Vehicle Directive. The Directive urges Member States to achieve a minimum procurement target for the share of clean vehicles as indicated in Table 4.

Hungary is given a target to procure a minimum of $8 \%$ of its trucks to achieve clean heavy-duty vehicle targets and $37 \%$ of its fleet in case of buses during the same period. As evident from Table 4, Member States are given roughly 4.5 times the

Table 4 - Minimum procurement targets for the share of clean heavy-duty vehicles in the total number of heavy-duty vehicles [39]

\begin{tabular}{||c|c|c|c|c||}
\hline \multirow{2}{*}{ Member States } & \multicolumn{2}{|c|}{ Trucks } & \multicolumn{2}{c||}{ Buses } \\
\cline { 2 - 5 } & $\begin{array}{c}\text { From 2 August 2021 to } \\
\text { 31 December 2025 }\end{array}$ & $\begin{array}{c}\text { From 1 January 2026 } \\
\text { to 31 December 2030 }\end{array}$ & $\begin{array}{c}\text { From 2 August 2021 to } \\
\text { 31 December 2025 }\end{array}$ & $\begin{array}{c}\text { From 1 January 2026 } \\
\text { to 31 December 2030 }\end{array}$ \\
\hline \hline Luxemburg & $10 \%$ & $15 \%$ & $45 \%$ & $65 \%$ \\
\hline Sweden & $10 \%$ & $15 \%$ & $45 \%$ & $65 \%$ \\
\hline Denmark & $10 \%$ & $15 \%$ & $45 \%$ & $65 \%$ \\
\hline Finland & $9 \%$ & $15 \%$ & $45 \%$ & $59 \%$ \\
\hline Germany & $10 \%$ & $15 \%$ & $45 \%$ & $65 \%$ \\
\hline France & $10 \%$ & $15 \%$ & $43 \%$ & $61 \%$ \\
\hline Hungary & $8 \%$ & $9 \%$ & $37 \%$ & $53 \%$ \\
\hline
\end{tabular}


minimum procurement target for electric buses compared to electric trucks. Mature market (electric bus) centric targets assignments by the EU Commission also contribute to slow uptake of immature markets (ET market).

\subsection{Disinformation (about TCO)}

Lack of information about the long-run benefits of ETs also weakens the case of ETs. Most of the companies are afraid of initial high investment because of a lack of incentives. Meanwhile, over the life period of use, the operational cost of ETs is much lower than that of conventional ICETs. Information about the cost of ownership and operational cost over the lifetime period of ETs should be provided by stakeholder companies and governmental authorities.

\subsection{Inefficient location of UCCs for ETs}

Statistics of responses showed that $77 \%$ of the UCCs are located away from the city centre in suburbs while only $23 \%$ of them are located near the city centre. As most of the UCCs are away from the city centre, it causes an increase in DADT. These extra miles require a longer range from trucks and make the case for ETs weaker. On the other hand, the other $23 \%$ of UCCs closer to the city centre support the case for ETs because a relatively shorter distance is covered to reach the city centre. The expectations of users are summarised in Table 5.

Table 5 - Summary of user expectations from authorities

\begin{tabular}{|c|c|}
\hline Barriers & Expectations \\
\hline \multirow{5}{*}{$\begin{array}{c}\text { Technological } \\
\text { constraints }\end{array}$} & Higher battery capacity and long life \\
\hline & Long-distance journeys \\
\hline & Short recharging time \\
\hline & Accessibility \\
\hline & Home/workplace charging \\
\hline \multirow{2}{*}{ Cost } & Close to ICET price \\
\hline & Lower than ICET trucks \\
\hline \multirow{3}{*}{$\begin{array}{c}\text { Government } \\
\text { support }\end{array}$} & Bridge price gap between ICETS \& ETs \\
\hline & Maintenance cost reduction \\
\hline & Facilitating EV deployment \\
\hline
\end{tabular}

\section{RECOMMENDATIONS}

We have summarised the recommendations according to the revealed barriers. The first barrier to the promotion of ETs is the lack of support from local authorities. Local authorities need to spread awareness about the potential benefits of ETs and offer attractive rewards. Rewards can be a support to initial purchase, exemption from duty/procurement taxes, discount in parking or road toll, incentivised provision of electricity, or charging infrastructure. To address the higher cost of purchase, several new business models are being deployed to minimise the extra upfront high cost of an ET purchase, as well as the financial risk and uncertainty of potential buyers. Some original equipment manufacturers (OEMs) are offering a service based on the concept of selling a mobility service. This strategy adopts the approach that the owner of the vehicle does not buy/own the batteries; these remain the property of the service provider.

A battery charging and battery swapping infrastructure system are being set up, and the customer is charged a monthly basic fee. Setting up charging/ battery swapping infrastructure also brings business opportunities for local authorities, OEMs, and companies working for provisions of fuels. Besides offering a competitive price for the vehicle, this model also overcomes the limited battery lifetime problem. The high cost of a vehicle can be managed by introducing attractive instalment plans. For example, Peugeot offered some attractive instalments for their customers. Peugeot is expanding its business from being only a vehicle manufacturer to being a mobility supplier. They offer a new business model with an "All-inclusive" package of less than $500 € /$ month for an EV. The contract includes a rental deal of 48-60 months with $10,000 \mathrm{~km}$ per year and a "buy-back" offer. Leasing is also offered.

Local authorities can introduce charging plans (off-peak charging benefits or contributions to the grid) to attract potential users and minimise the cost of charging.

Sharing of ETs fleet among different suppliers can also potentially lead to better organisation of the last mile deliveries and result in a better cost-benefit ratio. A storage system for the packages to be delivered can be introduced based on a utility function. The utility function can be based on factors affecting the cost of delivery from the supplier side. In the 
future, major barriers revealed can be quantified if enough trip-related information from logistics companies can be collected.

\section{CONCLUSIONS}

Our research has several important limitations. Hence, the results produced should be considered suggestive rather than conclusive. Only two vehicles from many possible comparison scenarios were considered for the TCO comparison and case building. Assessment of all-electric range requires daily driving demand, purpose of use, regional weather characteristics, and driving patterns of the users. With an actual performance of ETs over a lifetime yet to be realised, assessment of all-electric range can be part of future works. This paper contributes to the determination of the barriers restricting the progress of ETs. This is achieved through the design of a survey questionnaire with consideration of the most relevant factors. The questionnaire designed included the questions about the expectations of logistics professionals regarding ETs.

The main contributions of the paper are as follows:

- Identification of a list of barriers hindering the adoption of ETs.

- Determination of the expectations of logistics professionals from ETs and government.

- Based on the results of the questionnaire, several key findings were achieved.

- Location of the UCC affects the DADT.

- A multi-step delivery system is favourable for ETs.

- Lack of financial support from regional and local authorities is hindering the uptake of electric trucks.

The results have shown that if the delivery patterns are split into the multiple-step delivery system then range anxiety can be reduced. Relocation of the UCC can affectively decrease the DADT but it would be a rather expensive solution. Quantified barriers, trip data, existing charging network data, and considering possible future candidate sites (for installation of charging infrastructure) considered together can help in optimal siting of the charging infrastructure. Optimal siting of charging infrastructure can help in optimal vehicle routing. An algorithm can be generated and calibrated with input from real-time data to find an optimal solution considering all the barriers highlighted.
ETs require an uplift from multiple aspects for their strong growth in the logistics sector, as well an increase in travelling range/charge, better deployment of charging infrastructure en-route, and monetary support from local authorities.

\section{ACKNOWLEDGMENT}

The research was supported by the Ministry of Innovation and Technology NRDI Office within the framework of the Autonomous Systems National Laboratory Program.

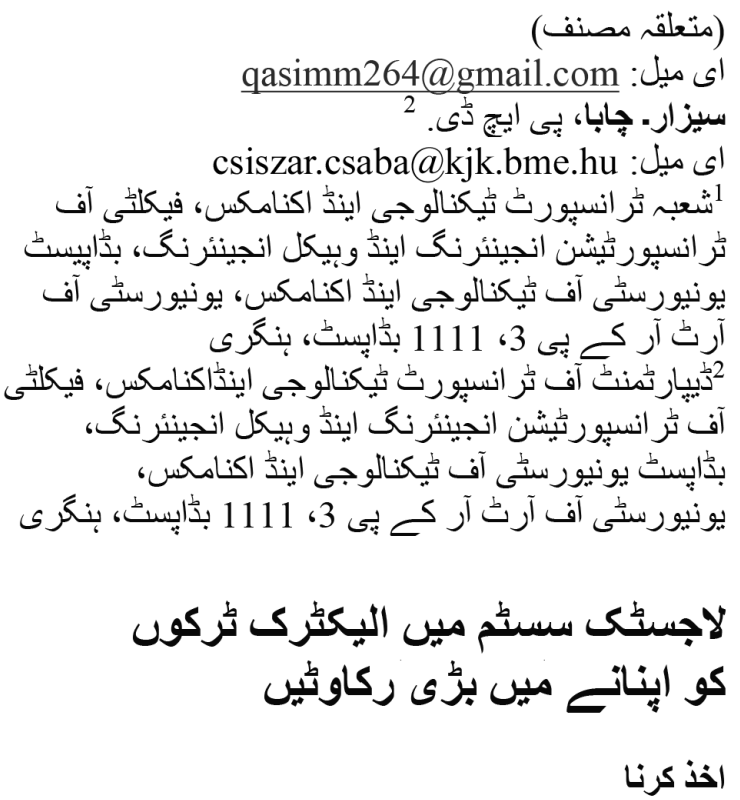

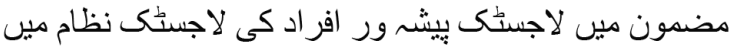

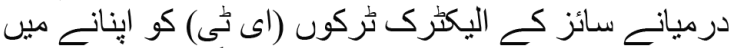

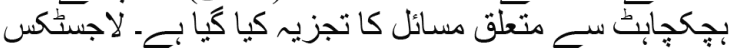

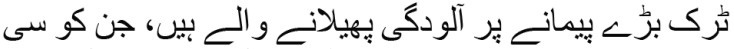

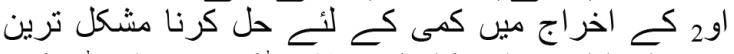

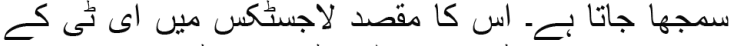

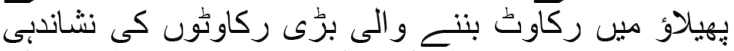

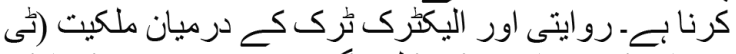

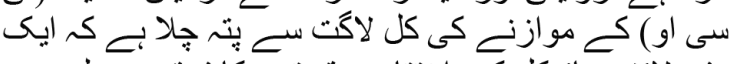

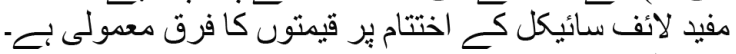

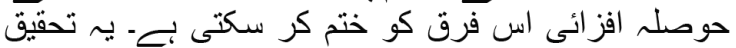

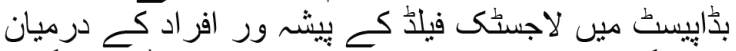

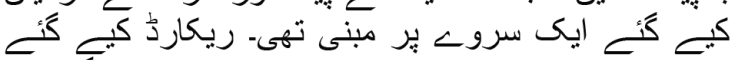

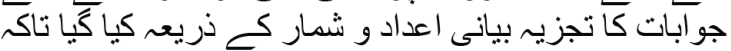

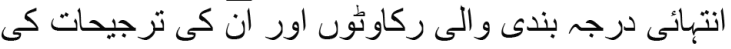

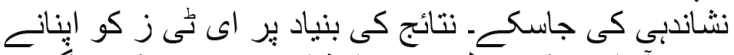

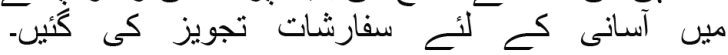

كليدى الفاظ

لاجستُك نظام؛ برقى ثرك؛ إِنانا؛ مر اعات؛ ملكيت كى كل لاكَت 


\section{REFERENCES}

[1] ACEA. Paper- $\mathrm{CO}_{2}$ emissions from heavy-duty vehicles - Preliminary $\mathrm{CO}_{2}$ baseline. European Automobile Manufacturer Association. Report number: Q3-Q4, 2019.

[2] Graichen J. Targets for the non-ETS sectors in 2040 and 2050. Öko-Institute; 2016.

[3] EU Transport in Figures - Statistical Pocketbook. Directorate General for Mobility and Transport; 2017.

[4] Ruesch M, Petz C. E-Commerce and urban freight distribution (home shopping): Best practice update. BESTUFS II, Deliverable D 2.4 Part I, 2008.

[5] Davis BA, Figliozzi MA. A methodology to evaluate the competitiveness of electric delivery trucks. Transportation Research Part E: Logistics and Transportation Review. 2013;49(10): 8-23. DOI: 10.1016/j.tre.2012.07.003

[6] Melo S, Baptista P, Costa Á. Comparing the use of small sized electric vehicles with diesel vans on city logistics. Procedia - Social and Behavioral Sciences. 2014;111: 350-359. DOI: 10.1016/j.sbspro.2014.01.068

[7] Grünjes HG, Birkner M. Electromobility for heavy-duty vehicles (HDV): the Siemens eHighway System. In: HVTT12 - $12^{\text {th }}$ International Symposium on Heavy Vehicle Transport Technology, 16-19 Sep. 2012, Stockholm, Sweden; 2012. p. 922-927.

[8] Van Rooijen T, Quak H. City Logistics in the European CIVITAS Initiative. Procedia - Social and Behavioral Sciences. 2014;125: 312-325. DOI: 10.1016/j.sbspro.2014.01.1476

[9] Feng W, Figliozzi MA. An economic and technological analysis of the key factors affecting the competitiveness of electric commercial vehicles: A case study from the USA market. Transportation Research Part C: Emerging Technologies. 2013;26: 135-145. DOI: 10.1016/j. trc.2012.06.007

[10] Best Practice Factory for freight transport. $7^{\text {th }}$ RTD Framework Programme; 2011.

[11] Calvo Ambel C, et al. Roadmap to climate-friendly land freight and buses in Europe. Brussles (SE): Transport \& Environment; 2017. 36 p. Available from: https://www. transportenvironment.org/publications/roadmap-climate-friendly-land-freight-and-buses-europe

[12] Nicolaides D, Cebon D, Miles J. Prospects for Electrification of Road Freight. IEEE Syst Journal. 2018;2(12): 1838-1849. DOI: 10.1109/JSYST.2017.2691408

[13] Rizet C, Cruz C, Vromant M. The Constraints of vehicle range and congestion for the use of electric vehicles for urban freight in France. Transportation Research Procedia. 2016;12: 500-507. DOI: 10.1016/j.trpro.2016.02.005

[14] Nocera B, Pungillo G, Bruzzone F. How to evaluate and plan the freight-passengers first-last mile. Transport Policy. 2020;49;1: 8-23. DOI: 10.1016/j.tranpol.2020.01.007

[15] Hosseinpour S, Chen H, Tang H. Barriers to the wide adoption of electric vehicles: A literature review based discussion. 2015 Portland International Conference on Management of Engineering and Technology (PICMET), 2-6 Aug. 2015, Portland, OR, USA. 2015. p. 2329-2336. DOI: 10.1109/PICMET.2015.7273259

[16] Li Y. Infrastructure to facilitate usage of electric vehicles and its impact. Transportation Research Procedia. 2016;14: 2537-2543. DOI: 10.1016/j.trpro.2016.05.337
[17] Figenbaum E. Perspectives on Norway's supercharged electric vehicle policy. Environmental Innovation and Societal Transitions. 2017;25: 14-34. DOI: 10.1016/j. eist.2016.11.002

[18] Earl T. Analysis of long-haul battery electric trucks in EU marketplace and technology, economic, environmental, and policy perspectives. Commercial Vehicle Workshop. 2018;8: 1718. Available from: 20180725_T\&E_Battery_ Electric_Trucks_EU_FINAL.pdf (transportenvironment. org) [Accessed 20th Jan 2021].

[19] Mruzek M, Gajdáč I, Kučera L, \& Gajdošík T. The possibilities of increasing the electric vehicle range. Procedia Engineering. 2017;192: 621-625. DOI: 10.1016/j.proeng.2017.06.107

[20] Ji S, et al. Electric vehicles in China: Emissions and health impacts. Environmental Science \&Technology. 2012;46(4). DOI: 10.1021/es202347q

[21] Lee D-Y, Thomas VM, Brown MA. Electric urban delivery trucks: Energy use, greenhouse gas emissions, and cost-effectiveness. Environmental Science \& Technology. 2013;47(14): 8022-8030. DOI: 10.1021/es400179w

[22] Lebeau P, Macharis C, Van Mierlo J. Exploring the choice of battery electric vehicles in city logistics: A conjoint-based choice analysis. Research Part E: Transportation. Logistics and Transportation Review. 2016;91: 245-258. DOI: 10.1016/j.tre.2016.04.004

[23] Sadek BA, Martin EW, Shaheen SA. Forecasting truck parking using Fourier transformations. Journal of Transportation Engineering, Part A: Systems. 2020; 146(8). DOI: 10.1061/JTEPBS.0000397

[24] Altan MF, Ayözen YE. The effect of the size of traffic analysis zones on the quality of transport demand forecasts and travel assignments. Periodica Polytechnica Civil Engineering. 2018;62(4): 971-979. DOI: 10.3311/ PPci.11885

[25] Quak H, Nesterova N, Rooijen TV, Dong Y. Zero emission city logistics: Current practices in freight electromobility and feasibility in the near future. Transportation Research Procedia. 2016;14: 1506-1515. DOI: 10.1016/j.trpro.2016.05.115

[26] Kovács G, Gubán M. Planning of optimal fuel supply of international transport activity. Periodica Polytechnica Transportation Engineering. 2017;45(4): 186-195. DOI: 10.3311/PPtr.10843

[27] Csonka B, Havas M, Csiszár C, Földes D. Operational methods for charging of electric vehicles. Periodica Polytechnica Transportation Engineering. 2020;48(4): 369-376. DOI: 10.3311/PPtr.15853

[28] Duarte G, Rolim C, Baptista P. How battery electric vehicles can contribute to sustainable urban logistics: A real world application in Lisbon, Portugal. Sustainable Energy Technologies and Assessments. 2016;15: 71-78. DOI: 10.1016/j.seta.2016.03.006

[29] Ližbetinová L, Hitka M, Kleymenov M. Motivational preferences of employees in requirements of Czech and Russian transport and logistics enterprises. International Journal of Maritime Science and Technology. 2018;65(4): 254-258. DOI: 10.17818/NM/2018/4SI.17

[30] Micieta B, Staszewska J, Binasova V, Hercko J. Adaptive logistics management and optimization through artificial intelligence. Communications-Scientific letters of 
the University of Zilina. 2017;19(2A): 10-14. Available from: http://komunikacie.uniza.sk/index.php/communications/article/view/205

[31] Chen TD, Kockelman KM, Khan M. Locating electric vehicle charging stations: Parking-based assignment method for Seattle, Washington. Transportation Research Record. 2013;2385(1): 28-36. DOI: 10.3141/2385-04

[32] Battery electric truck and bus energy efficiency compared to conventional diesel vehicles. California Air Resources Board, May 2018.

[33] Lebeau P, et al. Conventional, hybrid, or electric vehicles: Which technology for an urban distribution centre? The Scientific World Journal. 2015; 302867. DOI: $10.1155 / 2015 / 302867$

[34] Ramsey M. As electric vehicles arrive, firms see payback in trucks. The Wall Street Journal. Available from: https://www.wsj.com/articles/SB100014240527487045 84804575644773552573304 [Accessed 4th Dec. 2020].

[35] R\&D Batteries, Inc. Valence Advance Energy Storage Solution,U-Charge ${ }^{\circledR}$ U1-12RT. Specifications. Available from: http://www.valence.com [Accessed 7th Mar. 2021].

[36] Vijayagopal R, Rousseau A. Electric truck economic feasibility analysis. 2021;12(2): 75. DOI: 10.3390/ wevj12020075

[37] European Commission. Directorate-General for Mobility and Transport. Clean transport, urban transport. Alternative fuels for sustainable mobility in Europe. Available from: https://ec.europa.eu/transport/themes/urban/cleanbus_en [Accessed 9th Aug. 2021].

[38] European Commission. Directorate-General for Mobility and Transport. Clean transport, urban transport. Alternative fuels for sustainable mobility in Europe. Available from: https://ec.europa.eu/transport/themes/urban/ cpt_en [Accessed 9th Aug. 2021].

[39] Directive (EU) 2019/1161 of the European Parliament and of the Council of 20 June 2019 amending Directive 2009/33/EC on the promotion of clean and energy-efficient road transport vehicles. Official Journal of the European Union. Available from: https://eur-lex.europa.eu/ eli/dir/2019/1161/oj 